\title{
Target Lesion Identification
}

National Cancer Institute

\section{Source}

National Cancer Institute. Target Lesion Identification. NCI Thesaurus. Code C94520.

The identification of a lesion that is present at baseline, is measurable and is the primary target of the therapeutic intervention. 